\title{
Evaluation of Anatomical Variations of the Circle of Willis: Computed Tomography Angiography Study
}

\author{
MOHAMMED HAMDNALLAHA GHOBASHY, M.D.* and AMANY E. MOHAMMED HAMOUD, M.D.** \\ The Departments of Diagnostic Imaging \& Interventional Radiology* and Anatomy \& Embryology**, \\ Faculty of Medicine, Cairo University, Egypt
}

\begin{abstract}
Background: Circle of Willis (COW) main function is the brain protection from ischemia, as it ensures a constant and regular blood flow to the brain. The anatomy of Circle of Willis (COW) showed a wide variations in different individuals as regard age and sex.
\end{abstract}

Aim of Study: The current study was designed to elucidate the prevelance of $\mathrm{COW}$ variations in its anterior and posterior parts regarding age and sex, as well as the differences in the mean diameter of vessels forming the circle using Computed Tomography Angiography (CTA).

Material and Methods: The study was conducted on one hundred patients using cerebral CTA, Maximum Intensity Projections (MIP) and 3D reformatted images were assesed to determine the COW configuration and exclude the presence of any pathology. Frequency of variations in its two parts as regard age and sex. The diameters of arteries were measured and the mean difference were calculated.

Results: The study was designed on 100 patients $(52 \%$ male and $48 \%$ female) in two different age young group $<40$ and old age group > 40 . The mean diameters of arteries were higher in younger age group $56 \%$ compared to $44 \%$ in old age. Complete circle was encountered in $70 \%$ of cases, while $30 \%$ were incomplete. The variations recorded were $55 \%$ of cases in anterior part of the circle (Ant V) and $45 \%$ of cases in its posterior part (Post V) that showed statistically sig difference in anterior part than posterior part in the mean arteries diameters.

Conclusion: The circle of Willis showed different anatomical variations. Knowledge of the frequency of these variations is very important especially for surgery in cerebrovascular disease and in interventional procedures as a guide for entry in these procedures.

Key Words: Angiography-Circle of Willis - Computed tomography-Variations.

Correspondence to: Dr. Mohammed Hamdnallaha Ghobashy, The Department of Diagnostic Imaging \& Interventional Radiology, Faculty of Medicine, Cairo University, Egypt

\section{Introduction}

STROKES are classified into either ischemic or haemorrhagic stroke; ischemic stroke constitutes about $87 \%$ of stroke. Circle of Willis (COW) main function is the brain protection from ischemia, as it ensures a constant and regular blood flow to the brain [1]. The circle was firstly described by Sir Thomas Willis in 1664 as an anastomotic channel situated in the base of the brain, connecting both carotid and vertebral systems around the optic chiasm and infundibulum of the pituitary stalk in the suprasellar cistern [2].

The circle consisted of two portions anterior and posterior. Anterior circulation consisted of both left and right Internal Carotid Arteries (ICAs), segments (A1) of the left and right Anterior Cerebral Arteries (ACA) and one anterior communicating artery (AcomA) that communicate both ACA together and runs in the chiasmatic cistern below the rostrum of the corpus callosum. While posterior circulation consisted of left and right posterior communicating arteries (PcomA), the precommunicating part (P1) of left and right Posterior Cerebral Arteries (PCA) and the basilar artery before it divides at the upper border of the pons to form the left and right PCAs. From each ICA, a PcomA arises at the anterior perforated substance and runs back through the interpeduncular cistern to join the ipsilateral PCA [3].

Circle of willis might show many anatomical variations which is not rare, that's why awareness of these variations is very important for surgical and interventional radiological procedure [4]. Recent advances in Computed Tomography (CT) and multi detector Computed Tomography Angiography (CTA) make it easier as initial diagnosis for acute stroke and subarachnoid haemorrhage [5]. 
Regarding CTA, it is not affected by the patients' motion compared to MRA. Moreover, it is performed in seconds with high spatial resolution, also it allows an accurate images to be obtained from the patients for assessment of different arterial calibers [6]. It is used preoperatively for assessment of steno-occlusive carotid disease, for accurate assessment of the extracranial as well intracranial small arteries with a single scan [7].

Although some of the variations are with no clinical impact, most of them might explain unimprovement after surgical and interventional procedures. For example, fenestrations and duplications of the vessels may predispose to aneurysm formation, also foetal origin of PCA and accomapnied atherosclerotic disease of the carotid artery are more prone to ischemic events [8].

Previous literatures studied the COW anatomy and it's variation by Digital Subtraction Angiography (DSA) and 3D Time-of-Flight (3D TOF) Magnetic Resonance Angiography (MRA), but few studies have been published with multi-detector Computed Tomography Angiography (CTA). Therefore the aim of the current study was to evaluate the $\mathrm{COW}$ anatomical variations in its two parts regarding both age and sex, as well as the differences in the mean diameter of vessels forming the circle using the CTA.

\section{Material and Methods}

\section{Collection of cases:}

Retrospective study was done using multidetector CTA on a total of 100 patients, 52 males and 48 female. Mean age of the participants were 40 years (range, 20-60 years), the patient were classified into two groups: Young age group $<40$ years or old age group > 40 . People above 60 years old were excluded from the study as they might have atherosclerosis that will be misdiagnosed as hypoplasia. Patients with previous surgery, history of previous known anomalies or tumour were excluded from the study.

\section{Scaning study:}

For preparation of the study, all CTA data were transferred from the archive to a Vitrea workstation using $3 \mathrm{D}$ postprocessing options, multiplanar image reformatting (MPR) and 3-mm Maximum Intensity Projections (MIP). Projection slabs were done parallel and perpendicular to the anterior skull base for best view of the COW. MIP and ThreeDimensional Volume-Rendering (3DVR) images were revised. All examinations were evaluated by a senior radiologists with 15 years' experience with respect to COW anatomy. All images were processed on the Vitrea workstation, all measurements were taken by conventional imaging to ensure accuracy.

The examinations were performed in Andalusia hospital since January 2019 using (Toshiba Alexio, 16 MDCT, images using the following parameters (field of view $200-250 \mathrm{~mm}$, collimation 64 X 0.625 , pitch 0.39 , gantry rotation time $400 \mathrm{~ms}$, tube voltage $120 \mathrm{kVp}$, tube current $120-204 \mathrm{mAs}$, slice thickness 1- $2 \mathrm{~mm}$, dose-length product 312-626m Gycm).

The COW was evaluated according to the followings:

1- Each vessel segment was classified according to the diameter into 3 categories: Normal if its diameter more than or equal $0.8 \mathrm{~mm}$, hypoplastic if less than $0.8 \mathrm{~mm}$ or aplasia if invisible or absent [7]. The AcomA was considered normal if the junctions of the pre-communicating segment of both anterior cerebral arteries (A1) segments were very close with no spacing from each other. Both PCA and ICAs should be visualized carefully before determination of the PcomA.

2- The COW have two portions, anterior and posterior parts. For the anterior part, both $\mathrm{A} 1$ and AcomA were visualized and for the posterior part, (P1) and the PcomA were assessed on each side.

3- The anterior and the two posterior parts of the circle were classified into complete (if all vessels were normal) or incomplete (if any of the vessels were hypoplastic or absent). The results of the COW were recorded and tabulated then subjected for statistical analysis [7].

4- The diameters of arteries of the anterior and posterior circles regarding side were measured and the mean diameters were calculated.

5- Some of the terms used of our analysis: Fenestration is used for an arterial lumen that is separate into two separate lumens with distal convergence. Fetal origin of the PCA is used when PcomA is prominent with ipsilateral hypoplastic PCA and P1 segment (partial type fetal PCA) or absent PCA and P1 segment (full type fetal PCA) [9].

\section{Statistical study:}

Quantitative data were summarized as means, standard deviations and compared using Student's $t$-test and one-way Analysis-of-Variance (ANOVA). Any significant (sig) ANOVA was followed by post hoc Tukey test to detect which pairs of groups 
caused the significant difference. $p$-values $<0.05$ were considered statistically significant [10]. Calculations were made on Statistical Package of Social Science (SPSS) software Version 16.

\section{Results}

In the present study 100 patient were studied, $52 \%$ males and $48 \%$ females, $56 \%$ in young age group $<40$ years and $44 \%$ in old age group $\geq 40$ years. Complete circle were encountered in $70 \%$ of cases, while $30 \%$ were incomplete that showed highly sig difference. The COW variations showed highly sig difference between anterior and posterior parts and were recorded in $55 \%$ of cases in anterior part of circle (Ant V) compared to $45 \%$ of cases in posterior part of circle (Post V) (Table 1), Histogram (1).

Table (1): Diameter of arteries in male and female, young and old, complete and incomplete, anterior and posterior groups.

\begin{tabular}{lclcc}
\hline Groups & N\% & \multicolumn{1}{c}{ Mean \pm SD } & Std error & Sig. \\
\hline Male & $52 \%$ & $2.2168 \pm 0.7569$ & 0.04476 & 0.134 \\
Female & $48 \%$ & $2.3024 \pm 0.8774$ & 0.05188 & 0.134 \\
Young age & $56 \%$ & $2.3136 \pm 0.81133$ & 0.04623 & $0.032^{*}$ \\
Old age & $44 \%$ & $2.1886 \pm 0.7592$ & 0.04326 & $0.032^{*}$ \\
Complete & $70 \%$ & $2.2723 \pm 0.6897$ & 0.03687 & $0.000^{* *}$ \\
Incomplete & $30 \%$ & $1.7611 \pm 1.0657$ & 0.05697 & $0.000^{* *}$ \\
Ant V & $55 \%$ & $2.4264 \pm 0.8822$ & 0.05580 & $0.000^{* *}$ \\
Post V & $45 \%$ & $1.8164 \pm 0.6839$ & 0.04326 & $0.000^{* *}$ \\
\hline * : Sig. & & & & \\
**: Highly sig. & & &
\end{tabular}

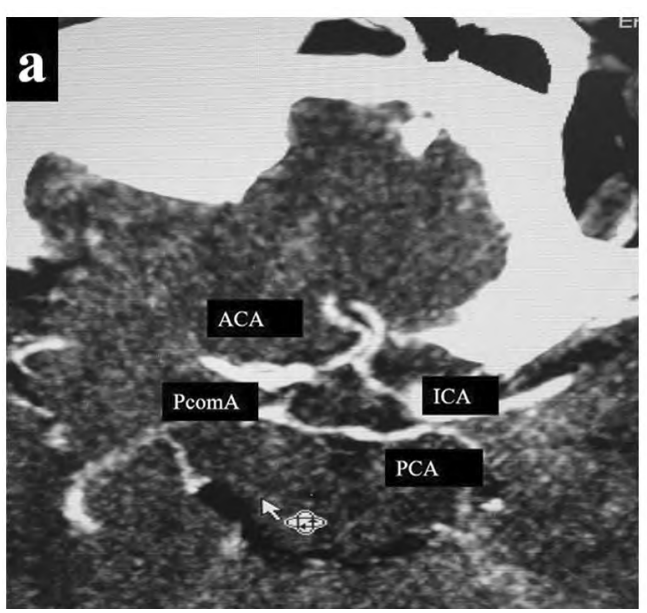

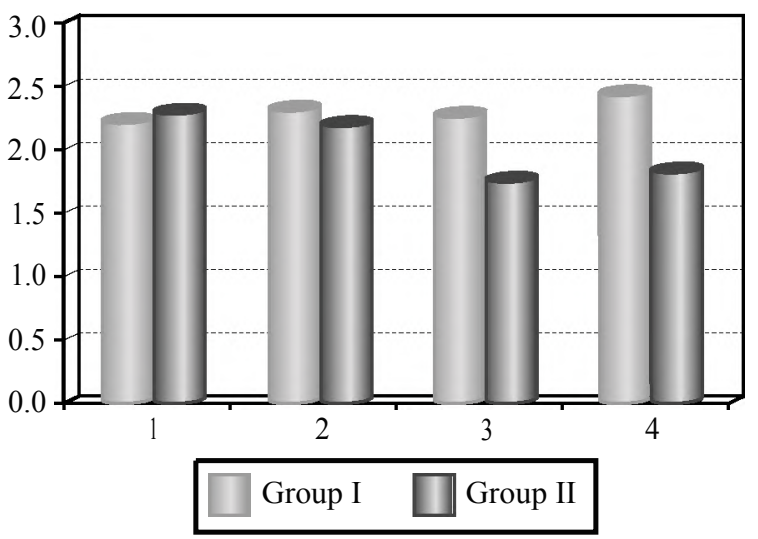

Histogram (1): Diameter of arteries in male and female, young and old, complete and incomplete, anterior and posterior groups.

1: Male and female. 2: Young and old age group 3: Anterior and posterior circle variation. 4: Complete and incomplete.

The circle was considered complete when both anterior and posterior portions were visible, both ICAs, A1 segment of ACAs and AcomA for normal anterior complete circle. While both PCAs, P1 segment and PcomA for normal posterior circle Fig. (1). Variations were most commonly found in the communicating arteries, less commonly in the cerebral arteries, and not detected in the ICAs. The anterior circle variations found were: Aplasia of A1 segment of ACA, giant aneurysm of A2 segment of ACA and fenestrated middle cerebral artery Fig. (2). The posterior circle variations found were hypoplasia, aplasia of PcomA and fetal origin of PcomA Fig. (3).

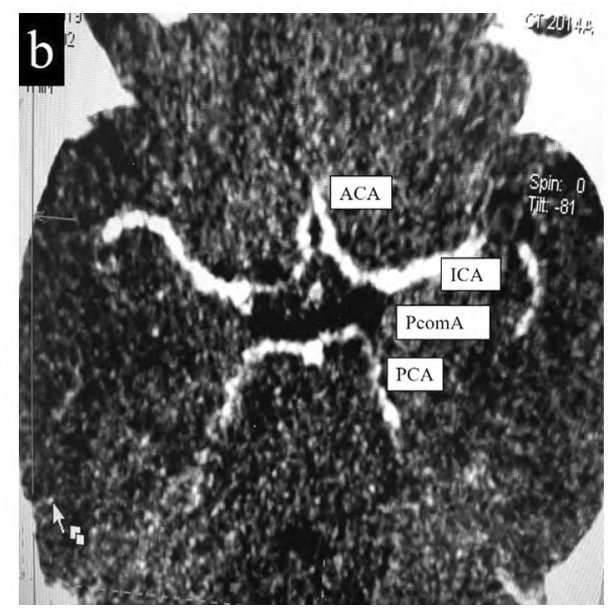

Fig. (1): Normal CTA view of COW: A) Complete circle with anterior part ACA and posterior part PcomA and PCA. B) Complete circle with ICA and normal appearance of both ACA and PCA with ICA, PcomA, PcomA and PCA. 

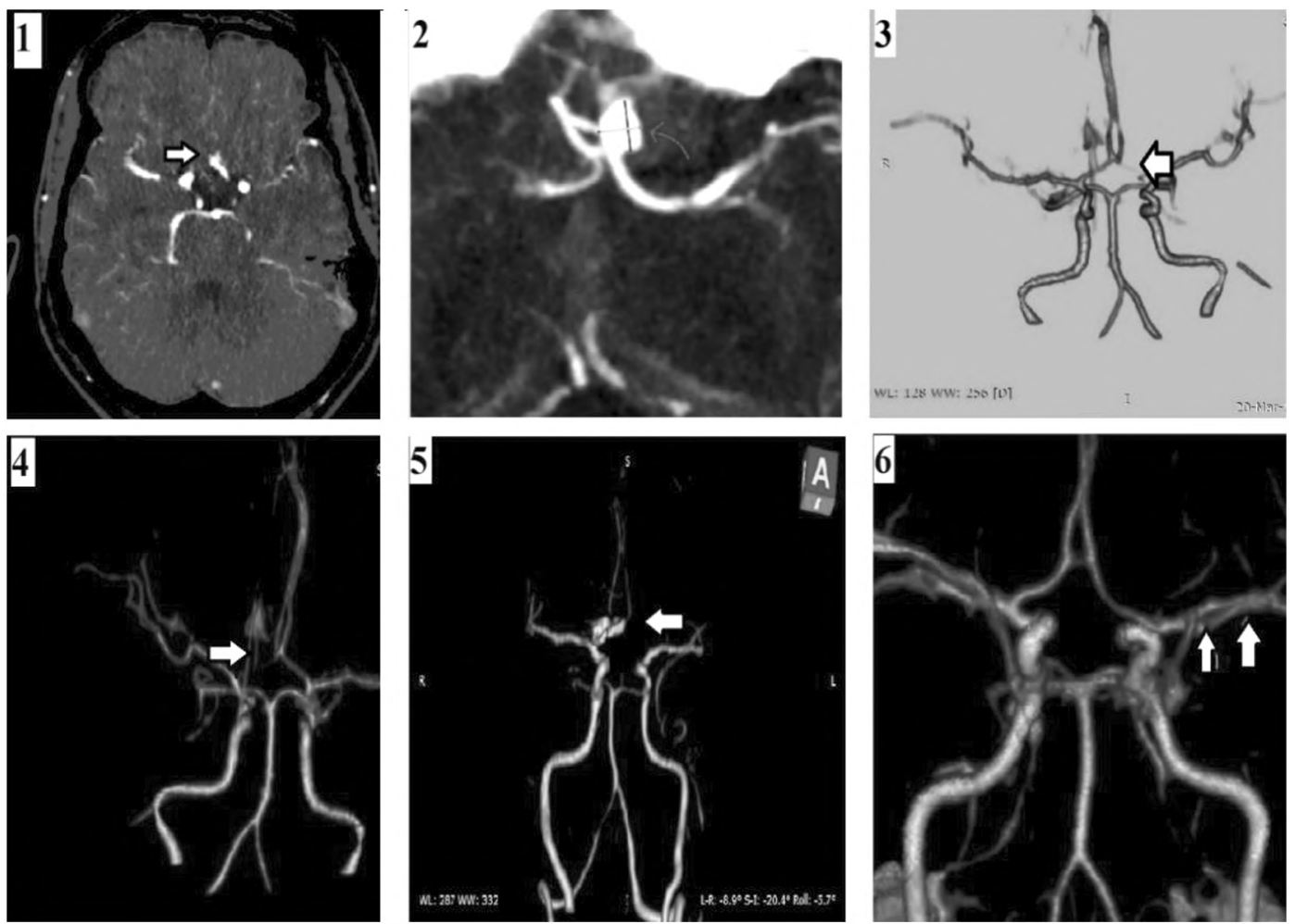

Fig. (2):The anterior circle variations in CTA. (1) Hypoplasia of A1 segment of right ACA (arrow). (2) Giant aneurysm of A2 segment of left ACA (arrow). (3) Aplasia of A1 segment of left ACA (arrow). (4) Hypoplasia of right A1 segment (arrow). (5) Aplasia of A1 segment of left ACA (arrow). (6) Fenestrated left middle cerebral artery.
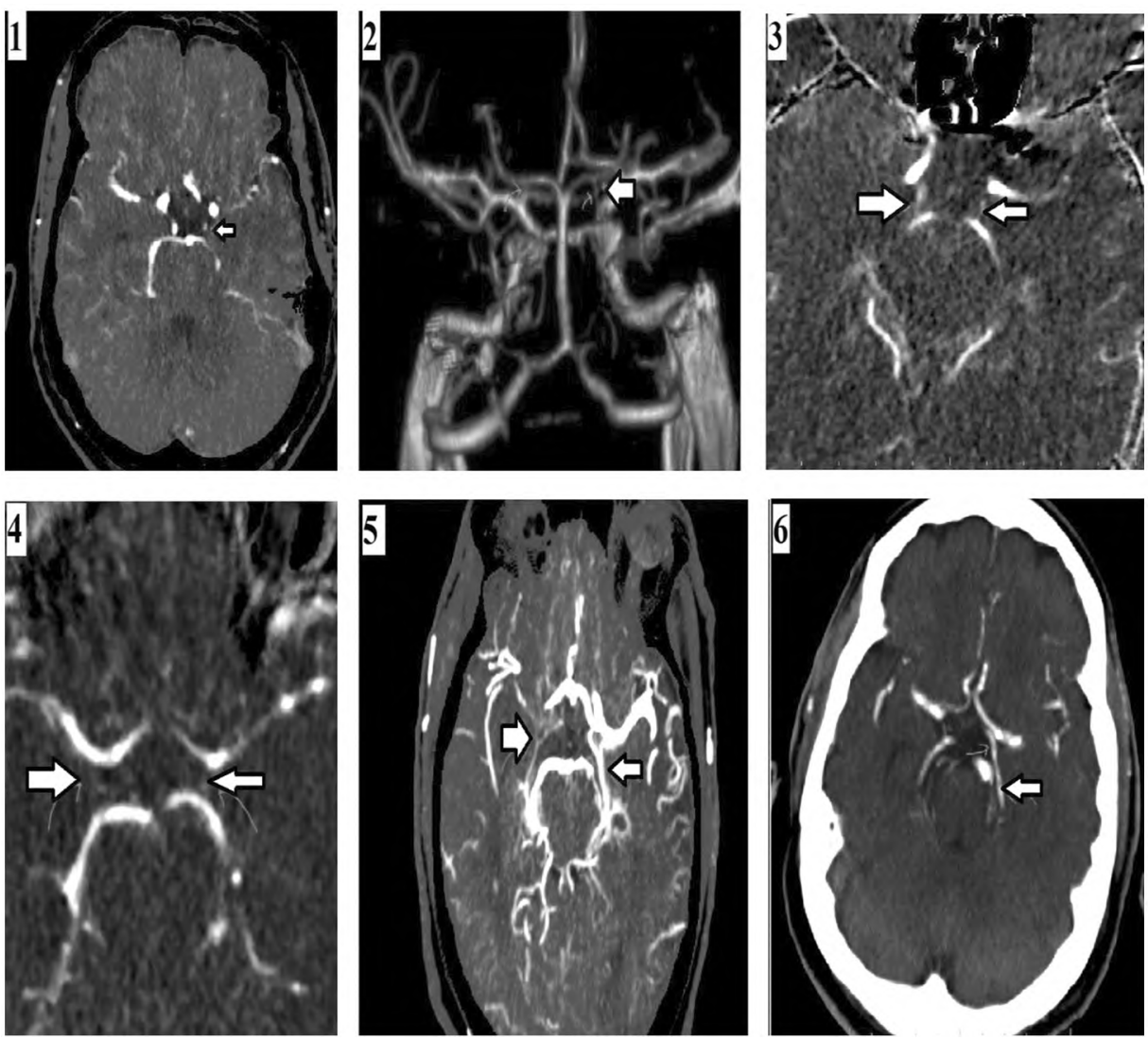

Fig. (3): The posterior circle variations in CTA. (1) Hypoplasia of left PcomA (arrow). (2) Right PcomA hypoplasia (arrow). (3) Bilateral PcomA hypoplasia (arrow). (4) Bilateral PcomA aplasia (arrow). (5) Aplasia of right PcomA with fetal origin of left PcomA (arrow). (6) Fetal origin of left PcomA (arrow). 
Table (2): Variation of arteries in male and female complete \& incomplete, male and female anterior V \& posterior $\mathrm{V}$, young and old age complete \& incomplete, young and old age anterior $\mathrm{V} \&$ posterior $\mathrm{V}$ groups.

\begin{tabular}{llll}
\hline Groups & N\% & Mean \pm SD & Sd error \\
\hline Male complete* & $35 \%$ & $2.3048 \pm 0.23$ & 0.18152 \\
Female complete* & $28 \%$ & $2.4112 \pm 0.09$ & 0.18201 \\
Male incomplete & $17 \%$ & $0.8882 \pm 0.05$ & 0.06357 \\
Female incomplete & $10 \%$ & $0.2200 \pm 0.0$ & 0.18201 \\
Male anterior V** & $29 \%$ & $2.3238 \pm 0.31$ & 0.09963 \\
Female anterior V** & $27 \%$ & $2.5375 \pm 0.08$ & 0.09762 \\
Male posterior V & $23 \%$ & $1.8462 \pm 0.11$ & 0.09963 \\
Female posterior V & $21 \%$ & $1.7842 \pm 0.2$ & 0.10160 \\
Young complete*** & $46 \%$ & $2.3832 \pm 0.15$ & 0.21999 \\
Old complete*** & $30 \%$ & $2.2748 \pm 0.14$ & 0.18719 \\
Young incomplete & $10 \%$ & $0.2400 \pm 0.08$ & 0.28333 \\
Old incomplete & $14 \%$ & $0.3786 \pm 0.0$ & 0.28333 \\
Young anterior V**** & $31 \%$ & $2.4957 \pm 0.42$ & 0.10041 \\
Old anterior V**** & $24 \%$ & $2.3382 \pm 0.22$ & 0.10627 \\
Young posterior V & $25 \%$ & $1.8636 \pm 0.09$ & 0.10041 \\
Old posterior V & $20 \%$ & $1.7564 \pm 0.0$ & 0.10627 \\
\hline
\end{tabular}

- *: Sig male complete versus male and female incomplete (.000), female complete versus male and female incomplete (.000).

- **: Sig male anterior $\mathrm{V}$ versus male and female posterior $\mathrm{V}(.000)$. Female anterior $\mathrm{V}$ versus male and female posterior $\mathrm{V}(.000)$.

- ***: Sig young complete versus young and old incomplete (.000), old complete versus young and old incomplete (.000).

- ****: Sig young age ant versus young and old post (.000), old ant versus young and old post (.000).

Male cases with complete circle (male complete) were found in $35 \%$ of cases compared to $28 \%$ female with complete circle (female complete) with no statistically sig difference. While $17 \%$ of male cases were incomplete circle (male incomplete) compared to $10 \%$ female with incomplete circle (female incomplete). Male complete were sig higher than male and female incomplete, as well female complete were sig higher compared to male and female incomplete (Table 2), Histogram (2). Male with anterior circle variation (male anterior V) were found in $29 \%$ of cases, while $27 \%$ of cases were recorded in female (female anterior $\mathrm{V}$ ). Male with posterior circle variation (male posterior V) were found in $23 \%$ of cases compared to $21 \%$ cases in female (female posterior). Male anterior were sig higher versus male and female posterior, as well female anterior were sig higher than male and female posterior (Table 2), Histogram (2). Young age group with complete circle (young complete) were found in $46 \%$ of cases versus $30 \%$ in old age (old complete), while young age with incomplete circle were found in $10 \%$ of cases compared to $14 \%$ cases in old age (old incomplete). Young and old complete were sig higher versus young and old incomplete (Table 2), Histogram (2). Young age with anterior circle variation (young anterior $\mathrm{V}$ ) were recorded in $31 \%$ of cases compared to $24 \%$ in old age (old anterior V). While $25 \%$ of cases in young age with posterior variation (young posterior $\mathrm{V}$ ) were found compared to $20 \%$ old age with posterior variation (old posterior $\mathrm{V}$ ). Young anterior $\mathrm{V}$ were sig higher compared to young and old posterior $\mathrm{V}$, also old anterior $\mathrm{V}$ were sig higher than young and old post V. Young ant $\mathrm{V}$ were sig higher versus young and old post $\mathrm{V}$, old ant $\mathrm{V}$ were sig higher versus young and old post V (Table 2), Histogram (2).

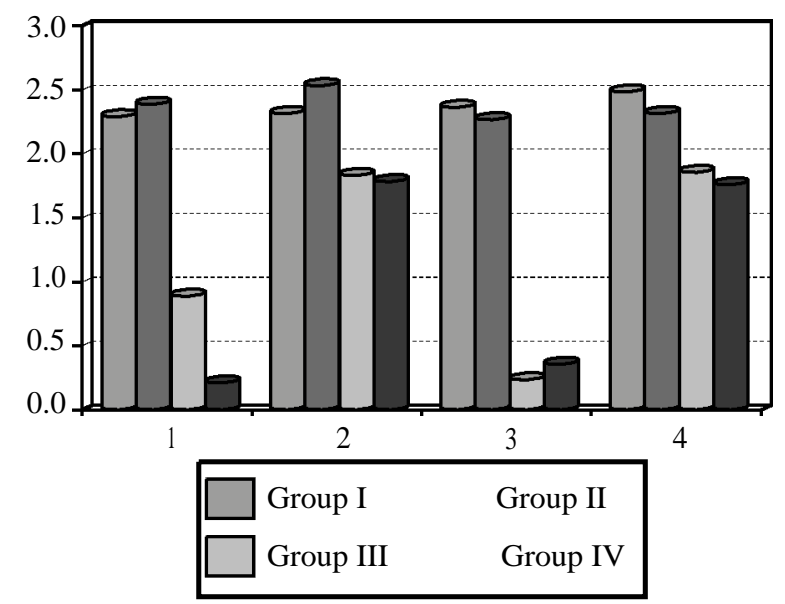

Histogram (2): The mean diameter of arteries in male and female complete \& incomplete, male and female anterior \& posterior, young and old age complete $\&$ incomplete, young and old age anterior $\&$ posterior groups.

1: Male complete, female complete circle, male incomplete, female incomplete circle.

2: Male anterior, female anterior variation. male posterior, female posterior variation.

3: Young complete, old complete, young incomplete, old incomplete.

4: Young anterior, old anterior. Young posterior, old posterior.

Table (3): The mean diameter of right and left arteries.

\begin{tabular}{|c|c|c|}
\hline Artery & Mean & Std error \\
\hline \multirow[t]{2}{*}{ Rt A1* } & M:2.2080 & \pm 0.35 \\
\hline & $F: 1.8240$ & \pm 0.07 \\
\hline \multirow{2}{*}{ Lt A1* } & M:2.3081 & \pm 0.34 \\
\hline & $F: 1.8265$ & \pm 0.0 \\
\hline \multirow[t]{2}{*}{ Rt ICA* } & M:3.0580 & \pm 0.12 \\
\hline & F:2.5964 & \pm 0.7 \\
\hline \multirow[t]{2}{*}{ Lt ICA* } & M:3.1560 & \pm 0.30 \\
\hline & $\mathrm{F}: 2.47432$ & \pm 0.5 \\
\hline \multirow[t]{2}{*}{ Rt ACA* } & M:2.8200 & \pm 0.61 \\
\hline & $F: 2.47432$ & \pm 0.7 \\
\hline \multirow[t]{2}{*}{ Lt ACA* } & M:2.9123 & \pm 0.8 \\
\hline & $F: 2.5440$ & \pm 0.2 \\
\hline \multirow[t]{2}{*}{ Rt $\mathrm{PcomA}^{\wedge}$} & M:1.9020 & \pm 0.05 \\
\hline & $F: 1.9012$ & \pm 0.0 \\
\hline \multirow[t]{2}{*}{ Lt PcomA^ } & M:1.5920 & \pm 0.21 \\
\hline & $F: 1.5920$ & \pm 0.2 \\
\hline \multirow[t]{2}{*}{ Rt P1* } & M:1.9580 & \pm 0.09 \\
\hline & $F: 2.0380$ & \pm 0.3 \\
\hline \multirow[t]{2}{*}{ Lt P1* } & M:1.8765 & \pm 0.50 \\
\hline & F:2.0380 & \pm 0.3 \\
\hline
\end{tabular}

N.B:

*: Sig difference between male and female.

$\wedge$ : Sig difference between right and left. 
The diameters of the arteries of anterior and posterior part of circles regarding side and sex were measured and the mean diameters were calculated. There were no statistically sig differences between the mean vessels diameters of the right and left arteries of the ICA, ACA, P1 and P1 except the PcomA which show sig difference. Mean artery diameters with regard to sex were measured in the current work, the average diameters of the ICA, ACA, A1 , P1 in were sig larger males than in females, while the average diameter of the PcomA was almost equal in males and females with no sig difference (Table 3).

\section{Discussion}

Blood supply of the brain is through both carotid and vertebral systems at the base of the brain anastomose together forming the circle of Willis. ICAs arteries and their branches supply the anterior part of the brain, while the vertebro-basilar system known as the posterior circulation supplies the posterior portion of the brain. It is considered as a main route for collateral blood flow in cerebrovascular diseases to preserve efficient cerebral perfusion. That's why awareness of the normal morphology of COW is very important prior any surgical intervention [11].

Threshold value that determine hypoplasia of vessels were unclear, many authors recommended a threshold value of $0.8 \mathrm{~mm}$ for hypoplasia [7], although others have recommended a value of $1 \mathrm{~mm}$ [6]. Previous studies showed that whenever the diameters of the communicating either AcomA or PcomA were less than $0.7 \mathrm{~mm}$ or the $\mathrm{A} 1$ or $\mathrm{P} 1$ was less than $1.0 \mathrm{~mm}$, the collateral circulation status is markedly affected. The authors added that when the diameters of the vessels constituting the COW were less than $0.5 \mathrm{~mm}$ the vessels can be regarded as absence [12]. The COW can quickly respond to decrease in brain blood flow by changing the blood direction through the communicating arteries [13]

Previously, the incidence of a complete anterior circle ranged from $70-90 \%$ in different studied groups [14]. In accordance with the present study as the prevalence of an entirely complete COW was $70 \%$. Although, most of autopsy studies, have reported a lower incidences of complete circles [15]. But few studies have reported variation of the COW in $40 \%$ with maximum variation in the Pco$\mathrm{mA}(50 \%)$ followed by the AcomA (40\%) [16]. The higher incidences of complete circles in female than male group and in younger age than older age group was observed in the current work, similar to previous studies [17]. The previous finding might be explained by two reasons, first the diameters of vessels in old patient seems to be narrower as a progress of atherosclerosis, second is the difference in the definition of hypoplastic vessels to determine whether the circle is complete or not.

In the present work a common variant in the posterior cerebral circulation is foetal type of PcomA, in which PcomA is larger than the P1 segment of PCA and supplies the bulk of the blood to the PCA, as there is a transient period in early fetal life, in which diameters of P1 and PcomA are equal but later in fetal life diameter of the $\mathrm{P} 1$ is smaller than diameter of PcomA. In adult, this parameter supposed to be changed in which $\mathrm{P} 1$ diameter is larger than the PcomA diameter. This change is due to occipital lobes development during the embryonic life and increases the blood supply which affect the posterior circle, and subsequently development of either adult or fetal type from transitional pattern [18]

In the current work fenestration of the middle cerebral artery were recorded and it was located in the origin of the artery, the reason for that fenestration remains unclear. One of the explanation for this anomaly was the early branching of the temporopolar artery from the middle cerebral artery [19]. Another variation were found in the present work was aplasia or hypoplasia of unilateral A1 segment of ACA, which might decrease the collateral blood supply and increase the risk for infarction. In this situation the contralateral ACA either enlarge to compensate for this or the anterior communicating instead [20]

One of the variation observed in the present work is unilateral and bilateral aplasia and hypoplasia in PcomA, same finding was reported by Tekale and Ambiye [21] who evaluated the COW in 100 healthy persons with 3D-TOF-MRA of the brain and all vessels of the circle were assessed by measuring the diameter and the authors concluded that the most common variation was hypoplasia and absence of the bilateral PcomA rather than any variations. The PcomA hypoplasia is considered as a key factor in ischemic stroke, even in the absence of ICA occlusion [22]

In the present work mean artery diameters with regard to side were measured and there were no statistically sig differences between the mean vessels diameters of the right and left arteries of the ICA, ACA and P1 except in PcomA, the only one that showed side sig difference. In agreement with the previous angiographic studies, the authors have also found minimal difference in arteries 
diameters between the right and left side [23]. Mean artery diameters with regard to sex were measured in the current work, the average diameters of the ICA, ACA, A1, P1 in males were sig larger than in females, while the average diameter of the PcomA was almost equal in males and females with no sig difference. Contrary to our result, the average diameter of the PcomA found to be larger in females than in males, while the average diameter of the P1 was larger in females than in males, but diameter of the ICA and the ACA were equal in males and females [24].

Some arteries of the COW might be invisible or they may not be present at all, and its intervention by radiologist is very difficult, that's why awareness of these different variations and any abnormalities prior to any operation for aneurysm, carotid endartectomy is crucial in ensuring safe surgery. Therefore we recommend using CTA for screening and pre-operative examination even in asymptomatic patients.

\section{Conclusion:}

The COW showed some anatomical variations. Awareness of these variations is very important for neurosurgeons and radiologists in interventional procedures. The CTA can be used pre-operatively to ensure normal and adequate circulation.

\section{References}

1- CHANDRA A., STONE C.R., DU X., LI W.A., HUBER M., BREMER R., GENG X. and DING Y.: The cerebral circulation and cerebrovascular disease III: Stroke. Brain Circ., 3 (2): 66-77, 2017.

2- MEYER A. and HIERONS R.: Observations on the history of the 'circle of Willis'. Med. Hist., 6: 119-30, 1962.

3- ROSNER J. and LUI F.: Neuroanatomy, Circle of Willis. In: Stat Pearls [Internet]. Treasure Island (FL): StatPearls Publishing, 2019.

4- HOKSBERGEN A.W.J., MAJOIE C.B.L., HULSMANS F.J.H. and LEGEMATE D.A.: Assessment of the collateral function of the circle of Willis: Three-dimensional timeof-flight MR angiography compared with transcranial color-coded duplex sonography. A.J.N.R. Am. J. Neuroradiol., 24 (3): 456-62, 2003.

5- TETSUKA S. and MATSUMOTO E.: Diagnosis of a subarachnoid hemorrhage with only mild symptoms using computed tomography in Japan. B.M.C. Neurol., 16 (1): 196-201, 2016.

6- KARATAS A., COBAN G., CINAR C., ORAN I. and UZ A.: Assessment of the Circle of Willis with Cranial Tomography Angiography. Med. Sci. Monit., 21: 264752, 2015.

7- VARGA A., Di LEO G., BANGA P.V., CSOBAY-NOVÁK C., KOLOSSVÁRY M., MAUROVICH-HORVAT P. and
HÜTTL K.: Multidetector CT angiography of the Circle of Willis: Association of its variants with carotid artery disease and brain ischemia. Eur. Radiol., (1): 46-56, 2019.

8- DIMMICK S.J. and FAULDER K.C.: Normal variants of the cerebral circulation at multidetector CT angiography. Radiographics, 29: 1027-43, 2009.

9- HE Z. and WAN Y.: Is fetal-type posterior cerebral artery a risk factor for intracranial aneurysm as analyzed by multislice CT angiography? Exp. Ther. Med., 15 (1): 83846, 2018.

10- EMSLEY R., DUNN G. and WHITE I.: Mediation and moderation of treatment effects in randomized controlled trials of complex interventions. Stat. Methods Med. Res., 19 (3): 237-70, 2010

11- RAVIKANTH R. and PHILIP B.: Magnetic resonance angiography determined variations in the circle of Willis: Analysis of a large series from a single center. Ci Ji Yi Xue Za Zhi, 31 (1): 52-9, 2019.

12- LI QI, LI J., LV F., LI K., LUO T. and XIE P.: A multidetector CT angiography study of variations in the circle of Willis in a Chinese population. J. Clin. Neurosci., 18 (3): 379-83, 2011

13- HARTKAMP M.J., VAN DER GROND J., VAN EVERDINGEN K.J., HILLEN B. and MALI W.P.: Circle of Willis collateral flow investigated by magnetic resonance angiography. Stroke, 30 (12): 2671-8, 1999.

14- KLUYTMANS M., VAN DER GROND J., VAN EVERDINGEN K.J., KLIJN C.J., KAPPELLE L.J. and VIERGEVER M.A.: Cerebral hemodynamics in relation to patterns of collateral flow. Stroke J., 30 (7): 1432-9, 1999.

15- VAN SEETERS T., HENDRIKSE J., BIESSELS G.J., VELTHUIS B.K., MALI W.P., KAPPELLE L.J. and VAN DER GRAAF Y.: SMART Study Group. Completeness of the circle of Willis and risk of ischemic stroke in patients without cerebrovascular disease. Neuroradiology, 57: 1247-51, 2015 .

16- GUNNAL S.A., FAROOQUI M.S. and WABALE R.N.: Anatomical variations of the circulus arteriosus in cadaveric human brains. Neurol. Res. Int., 2014: 687281, 2014.

17- IQBAL S.: A comprehensive study of the anatomical variations of the circle of Willis in adult human brains. J. Clin. Diagn. Res., 7: 2423-7, 2013.

18- VAN OVERBEEKE J.J., HILLEN B., TULLEKEN C.A.: A comparative study of the circle of Willis in fetal and adult life. The configuration of the posterior bifurcation of the posterior communicating artery. J. Anat., 176: 45$54,1991$.

19- NUSSBAUM E.S., DEFILLO A., JANJUA T.M. and NUSSBAUM L.A.: Fenestration of the middle cerebral artery with an associated ruptured aneurysm. J. Clin. Neurosci., 16: 845-7, 2009.

20- YAMAGUCHI K., UCHINO A., SAWADA A., TAKASE Y., KURODA Y. and KUDO S.: Bilateral anterior cerebral artery territory infarction associated with unilateral hypoplasia of the A1 segment: Report of two cases. Radiat. Med., 22: 422-5, 2004. 
21- TEKALE V.M. and AMBIYE M.V.: A study of circle of Willis by MR angiography. Int. J. Anat. Res., 4: 25422546, 2016.

22- CHUANG Y.M., LIU C.Y., PAN P.J. and LIN C.P.: 'Posterior communicating artery hypoplasia as a risk factor for acute ischemic stroke in the absence of carotid artery occlusion', J. Clin. Neurosci., 15 (12): 376-81, 2008.
23- VOLJEVICA A., TALOVIC' E., PEPIC' E., KAPIC' A.P.: Morphometric analysis of Willis circle arteries. Arch. Pharma. Pract., 4: 77-82, 2013.

24- CHEN H.W., YEN P.S., LEE C.C., CHEN C.C., CHANG P.Y., LEE S.K., et al.: Magnetic resonance angiographic evaluation of circle of Willis in general population: A morphologic study in 507 cases. Chin. J. Radiol., 29 (5): 223-9, 2004.

\section{تقييم الإختلافات التشريحية لدائرة ويليس،

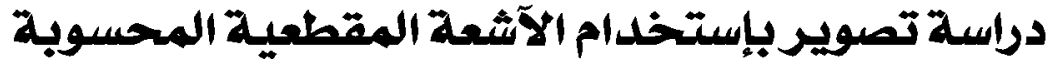

المقدمة: هناك تنوع كبير في الوصف التشريحى لدائرة ويليس لمختلف الآتراد في الفئات العمرية المختلفة. والغرض من هذه الدراسة تحديد نسبة التنوع المختلف لدائرة ويليس فيما يتعلق بالعمر والجنس.

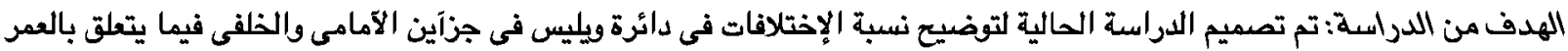

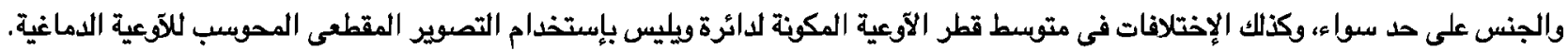

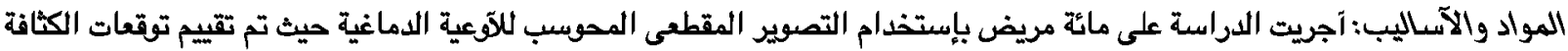

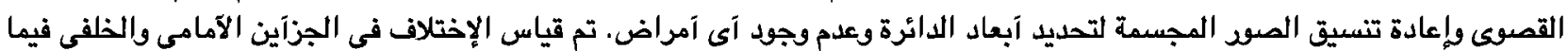
يتعلق بالعمر والجنس، فضلاً عن آقطار الثرايين وتم حساب متوسط الفرة الفرق بينهم.

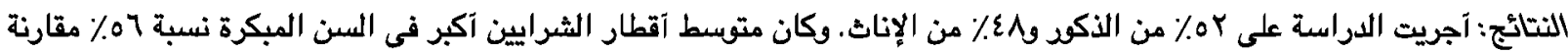

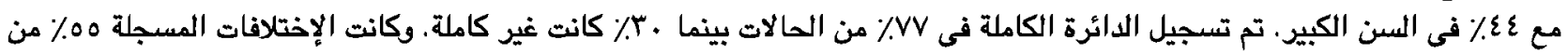

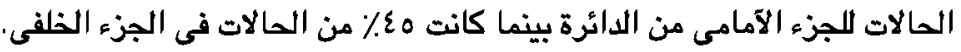

الملخص: آظهرت دائرة ويليس إختلاف تثريحى ومعرفة نمط هذه الإختلافات ذو آهمية لجراحى المخ والآعصاب وآخصائى الآشعة فى الإجراءات التداخلية كمرشد للاخل دائرة في هذه الإجراءات. 